\title{
BEARING CAPACITY OF SINGLE-ANGLE COMPRESSION MEMBER: EXPERIMENTAL AND NUMERICAL INVESTIGATION
}

\author{
Javad Majrouhi Sardroud and Mohammad Hossein Zaghian
}

\author{
Islamic Azad University, Central Tehran Branch, Faculty of Technology and Engineering, Civil \\ Engineering, Tehran,Iran; j.majrouhi@iauctb.ac.ir, moh.zaghian.eng@iauctb.ac.ir
}

\begin{abstract}
This study was conducted to investigate the load-bearing capacity of a single angle column under various loading conditions to determine the loading condition offering the highest loadbearing capacity. In all cases, the load is transferred through one leg (or two legs) of the angle which has a smaller cross-sectional area compared to the total area of the angle profile. The main objective of this study is to develop almost all of the possible support conditions for the single angle section and carry out laboratory tests on the chosen specimens to determine the most suitable one. Also, there are some finite element investigations done using ABAQUS software to find out the maximum forces in which all the elements of the structures remain their linear behavior and the stress spots concentration. Based on the obtained results, it is possible to increase the axial critical load of a single angle by using the connections at the main axis of the section.
\end{abstract}

\section{KEYWORDS}

Bearing capacity, Buckling, Compression angle, Single angle, Stability, Optimization, FEM

\section{INTRODUCTION}

Single angle section (SAS) is one of the first structural shapes and is commonly used as a traditional structural member, for instance it can be utilized as a member of steel bridges, radio towers, and Trusses [1]. This section is usually available with an association of two equal legs and it is the shape of the section that makes it unique because of the easy manufacturing and transportation [2]. Single angle is preferred by construction engineers, because its two perpendicular legs provide a superior way of connection with other structural members. However, SAS formed members are found to be difficult shapes, analytically, as they are difficult to apply force (and moment) on them [1]. The points mentioned above, have motivated researchers to conduct a great number of studies.

Regarding economic aspects of the plan, in steel profiles made as thin walls (like angle profile), buckling is one of the most important problems which can occur [3]. Buckling appears in two forms (i.e., partial and overall), both forms are related to loading conditions and to the geometry of the member.

\section{LITERATURE REVIEW}

Botelho et al (2021) [2] have focused on the torsional buckling behavior of starred angle rolled sections under compression. They found out that compared to their experimental and numerical results, Eurocode 3 prediction, presents more significant discrepancies. Veerendra 
Kumar Shukla et al (2021) [5] have provided a new insight on Analysis of a Cruciform-Leg Transmission Line Tower. Their paper gives some suggestions for angle connection. Sayed (2020) [6] numerically investigated single-angle steel member under tension load with damage in the unconnected leg and he found out that the damage ratio can affect the stress distribution and load capacity. Fábio Paiva and Rui C. Barros (2020) [7] developed a numerical analysis of the buckling resistance of a single angle in OPENSEES. The study contains hysteretic behavior of angle profile under cyclic loads. Xiaonong Guo et al (2020) [8] presented an investigation about the mechanical behavior of in-service axial compression angle steel members. They concluded that the influence of initial load on ultimate bearing capacity of steel members can be ignored when the initial stress is less than 0.4fy. Masoud Mirtaheri et al (2019) [9] carried out an experimental research to investigate the role of a new connection in steel structures and they found out that the resistance of connections in steel structures plays an important role in decreasing the damage from the progressive collapse. Tong and Guo (2018) [10] investigated the elastic buckling and hysteretic behavior of steel angles. They suggested ratios to prevent local buckling failure. Li Tian et al. (2018) [11] carried out a study about single-angle compression members, and according to their test results, a model was developed to determine the effective slenderness ratios of single-angle members with both legs bolted at the end. Markus Kettler et al. (2017) [12] tested 300 steel angles in compression and also conducted some numerical investigations. They concluded that the end support of the gusset plate plays an important part in the compression Member (angle) capacity. Amit Jain and his colleagues (2014) [1] studied the lateral-torsional buckling of laterally unsupported single angle sections loaded along a geometric axis and simulated this buckling using the ABAQUS software. For this purpose, they placed an equal leg angle in four different modes under the bending moment. The results of this research showed that IS800-2007 does not provide sufficient instructions for single angle's modelling. Giuseppe Brando et al. (2013) [13], used the finite element method (FEM) to determine the critical load of perforated single angle, the result showed that having less than 9\% holes affects the critical load. Ruhi Aydin et al (2011) [14] found out that it would be useful to set a limiting value for the second order when a design code is used. Liu and Hui (2010) [15] applied a FEM analysis in steel single angle beam-columns and recognized a significant non-compliance between "AISIC-2005" and the performed FEM analysis. Also, he and his colleagues (2008) [16], test 28 single angles and their conclusion was: "AISC Specification 2005 equations intended for doubly symmetric sections provide improved capacity estimates of eccentrically loaded single angles failing by flexural-torsional buckling".

\section{THE FINITE ELEMENT METHOD IN SHELLS}

The Finite Element Method (FEM) has been widely used to solve different kinds of engineering problems for years. This method is recognized as a reliable method to analyze civil engineering complications in spite of some unsolved issues [17]. In the FEM modelling, the structure is fractionalized into a limited number of elements (usually in rectangular or triangle shapes) which are connected to each other in the knots and borders between the supposed elements so that the balance and conformity in every knot and the direction of the borders between elements can be satisfied [18].

\section{THE COMPRESSION TEST ON THE SINGLE ANGLE PROFIL}

This study presents the buckling and single angle load-carrying capacity under the effect of compression load from a new aspect. Angles usually are loaded in the form of a plate coupling to a flange. In this study, for finding a better way of loading angles, some states of the case were 
studied to enhance the safety factor and determine the best outcome for various experimental and numerical methods. All the tests were conducted in a material laboratory.

\section{The technical characteristics of used steel and the geometric features of the profile}

In this modelling, construction steel (St-37) was used. The modulus of it, yield point, and Poisson's ratio were assumed to be $201035.5 \mathrm{MPa}, 230.8 \mathrm{MPa}$, and 0.3 , respectively. There is an information about the used angle profile in Figure 1 and Table 1.

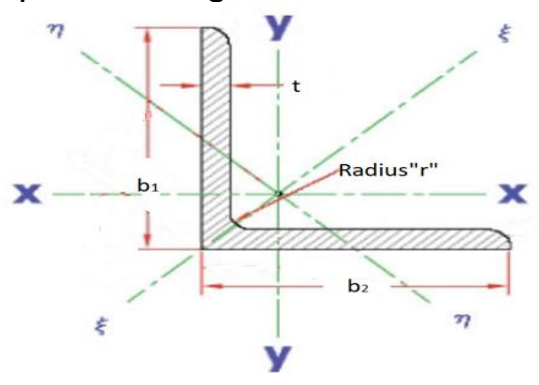

Fig. 1 - Axes are mentioned in Table 1

Tab. 1 - Some of the Specifications used single angel

\begin{tabular}{ccccc}
\hline Mechanical Properties ST-37 & $F_{y}=230.8 \mathrm{MPa}$ & $\mathrm{G}=7732.1 \mathrm{MPa}$ & $\mathrm{E}=201035.5 \mathrm{MPa}$ & $\mathrm{U}=0.3$ \\
\hline Specifications Section (Figure1) & $\mathrm{b}_{1}=40 \mathrm{~mm}$ & $\mathrm{~b}_{2}=40 \mathrm{~mm}$ & $\mathrm{t}=4 \mathrm{~mm}$ & $\mathrm{~A}=308 \mathrm{~mm}^{2}$ \\
\hline The radius of gyration (Figure1) & $\mathrm{r}_{\zeta}=15.2 \mathrm{~mm}$ & $\mathrm{r}_{\eta}=7.8 \mathrm{~mm}$ & $\mathrm{r}_{x}=12.1 \mathrm{~mm}$ & $\mathrm{r}_{\mathrm{y}}=12.1 \mathrm{~mm}^{2}$ \\
\hline Second Moment of Area (Figure1) & $\mathrm{I}_{\zeta}=7.09 \mathrm{~mm}^{4}$ & $\mathrm{I}_{n}=1.86 \mathrm{~mm}^{4}$ & $\mathrm{I}_{x}=4.48 \mathrm{~mm}^{4}$ & $\mathrm{l}_{\mathrm{y}}=4.48 \mathrm{~mm}^{4}$ \\
\hline
\end{tabular}

\section{Preparing the samples of the test}

Six samples, each $1 \mathrm{~m}$ long, were cut. Except for one sample (sample No.1), the rest were loaded while the $\mathrm{T}$ shaped pieces were connected to them. Also, to transfer the load in five samples, some T-shaped samples were prepared and welded to the end of angles with an E60 electrode on specific spots.

To make the geometry of the models, instead of a gusset plate, a T-bar web was used in the simulations and tests. The T-bar web and flange acted as the gusset plate and the loading plate, respectively. In all models, a $40 * 40 * 4$ angle (length $=1000 \mathrm{~mm}$ ) was used. On both ends of this angle, two halves of an IPE 80 T-bars (length $=40 \mathrm{~mm}$ ) were installed; however, in one model (sample No.1), only two gusset plates were installed. Each model represented a different case of the angle to the T-bar joint. Table 2 gives the 3D representation, name, and description of each model. 
Tab. 2 - The geometry of the models

Code of
Model

\section{Experimental plan}

The apparatus used for conducting the tests was the $500 \mathrm{KN} \mathrm{AMSLER}$, which was able to measure the deformation. The accuracy of this machine is $0.005 \mathrm{~mm}$. Also, two codes were used [19] [20]in this study and according to these codes, the rate of stressing was considered 110 $\mathrm{Mpa} / \mathrm{min}$. The temperature of the laboratory was approximately $26^{\circ} \mathrm{C}$ during the testing processes. Figure 2 shows model No.5 under testing process and all samples after mechanical tests. 


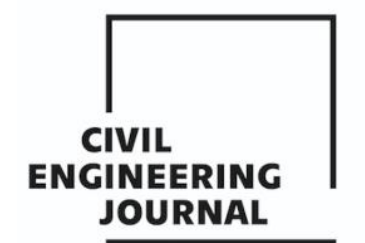

Article no. 25

THE CIVIL ENGINEERING JOURNAL 1-2021

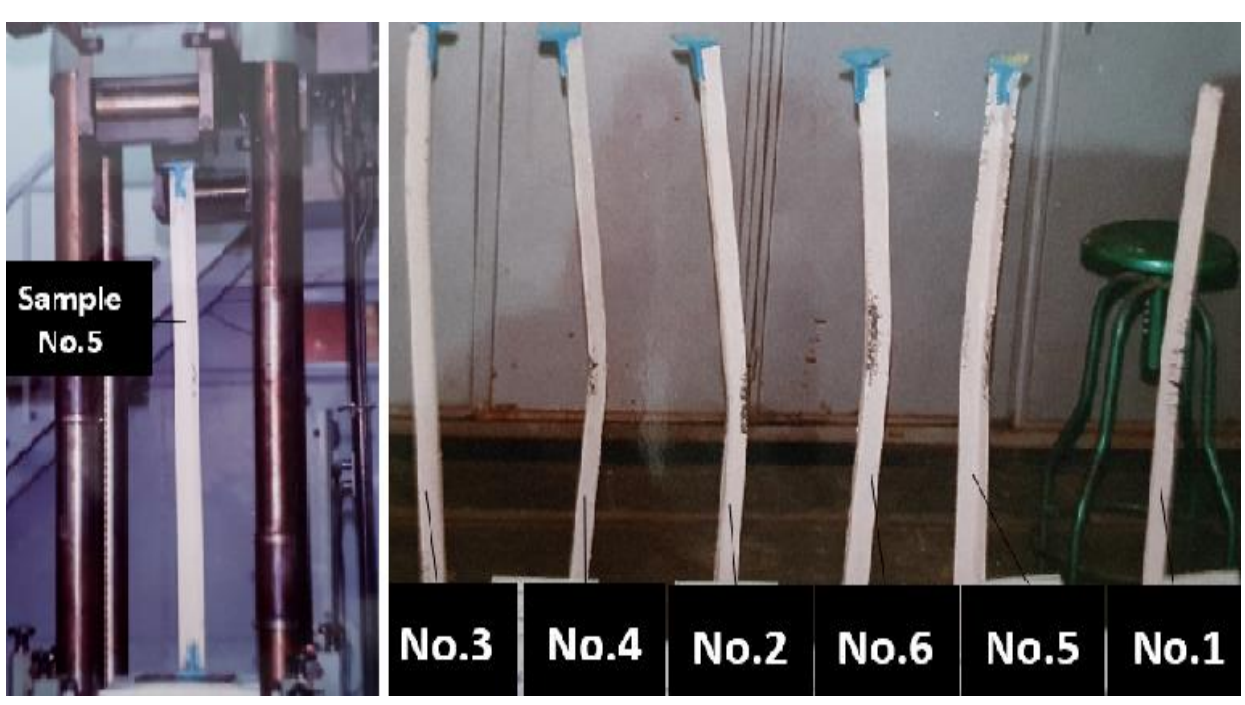

Fig. 2 - model No.5 under loading process and all samples after mechanical tests

The experiment was conducted as follows: First, the sample was set between two jaws of the apparatus and, after setting the two layers of sponge on both ends between the samples and the jaws of the apparatus, a small load was applied, and the sample was fixed by a balancer in a vertical mode. Afterwards, the load was applied gradually, the ultimate bearing capacity was measured, and the force diagram was plotted. The changes in the length were recorded using the apparatus. All six samples were set under compressive forces. The diagram of sample No.5 is depicted in Figure 3 as a sample. Also, in Figure 4, there are two views of sample No.2 under the loading process.

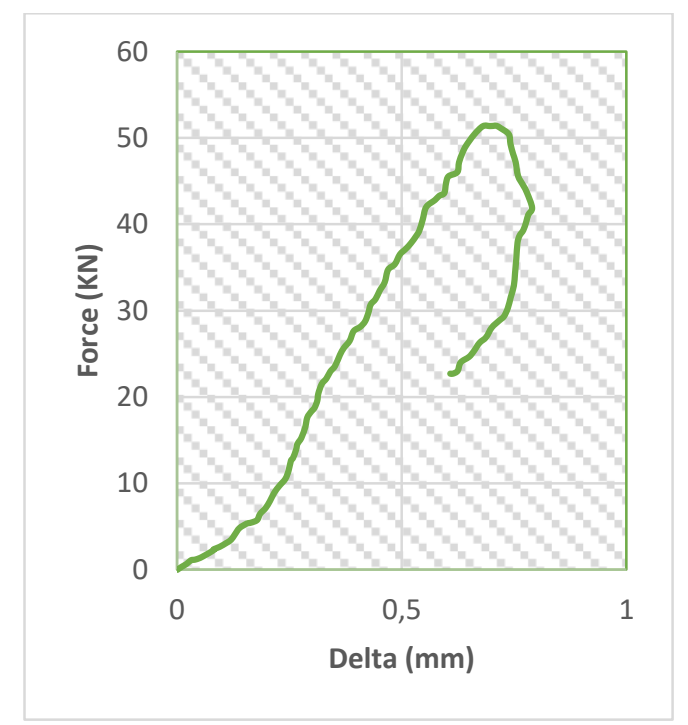

Fig. 3 - Force-Delta Diagram of sample No.5 

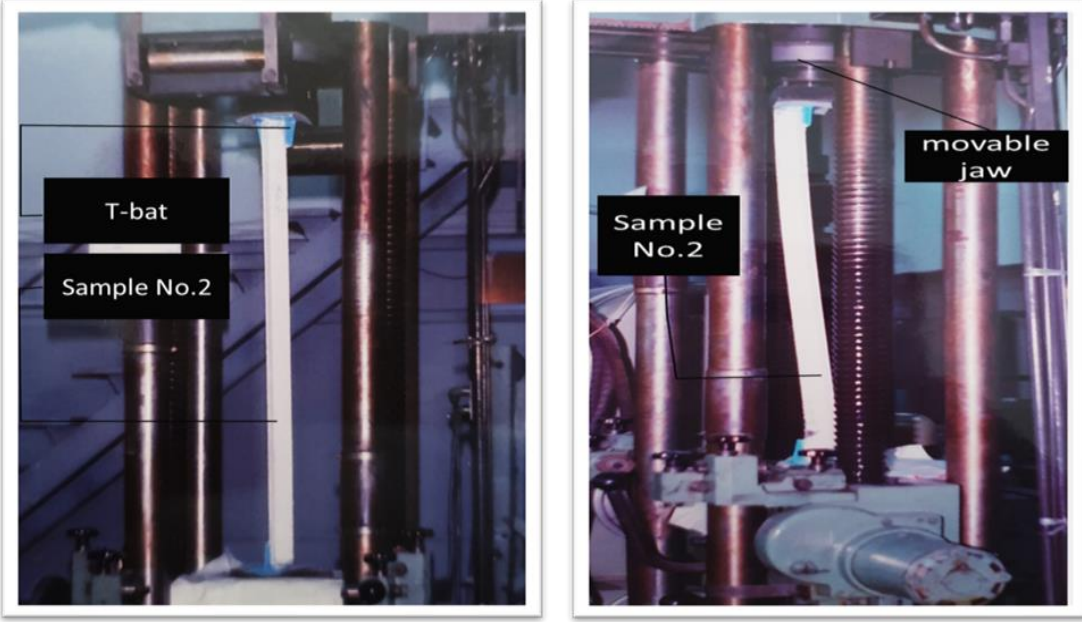

Fig. 4 - Two views of sample No.2 under the loading process

\section{The Result of compression test}

The ultimate capacity of a single angle profile was measured in all loading modes. Sample No.1 had the highest load capacity. The loading capacity of Sample No.5 is lower than sample No.1 by $6.2 \%$. Sample No.4 had the lowest load capacity ( $26.38 \mathrm{KN})$. The loading capacities of sample No.2 and sample No.3 are $38.15 \mathrm{KN}$ and $35.21 \mathrm{KN}$, respectively. The summary of these tests is presented in Figure 5.

In terms of buckling, under compression forces, steel members can experience five types of buckling: Local Buckling, Distortional Buckling, Overall Flexural Buckling, Overall Torsional Buckling, and Overall Flexural-Torsional Buckling [21]. In all of the samples in this study, Overall Flexural Buckling occurred.

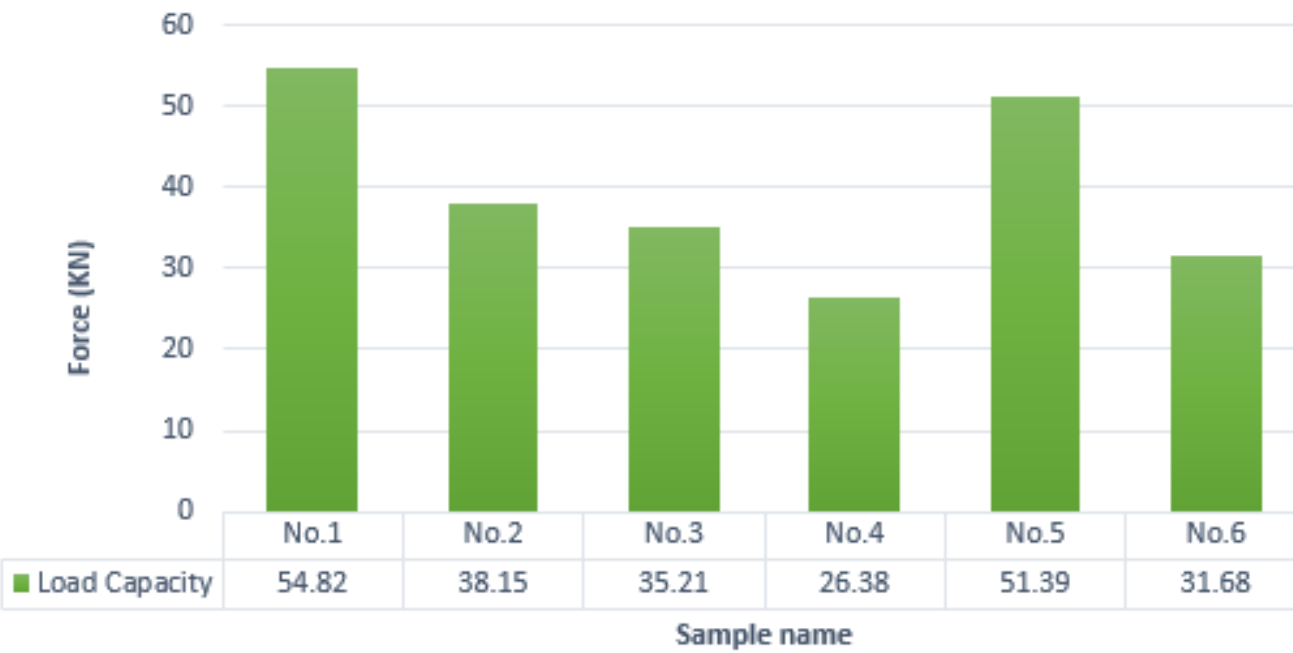

Fig. 5 - The load capacity for the samples (experimental) 


\section{NUMERICAL MODELLING}

This section examines 6 cases of angle to gusset plate joint. The computer modelling was done using ABAQUS software. The purpose of this section is to find out the maximum force in which all elements of the structure remain their linear behavior. In other words, the maximum force in which the cases behave absolutely linear and none of the elements reach to yield strength. Figure 6 shows the simulation of model No.4 and its different parts.

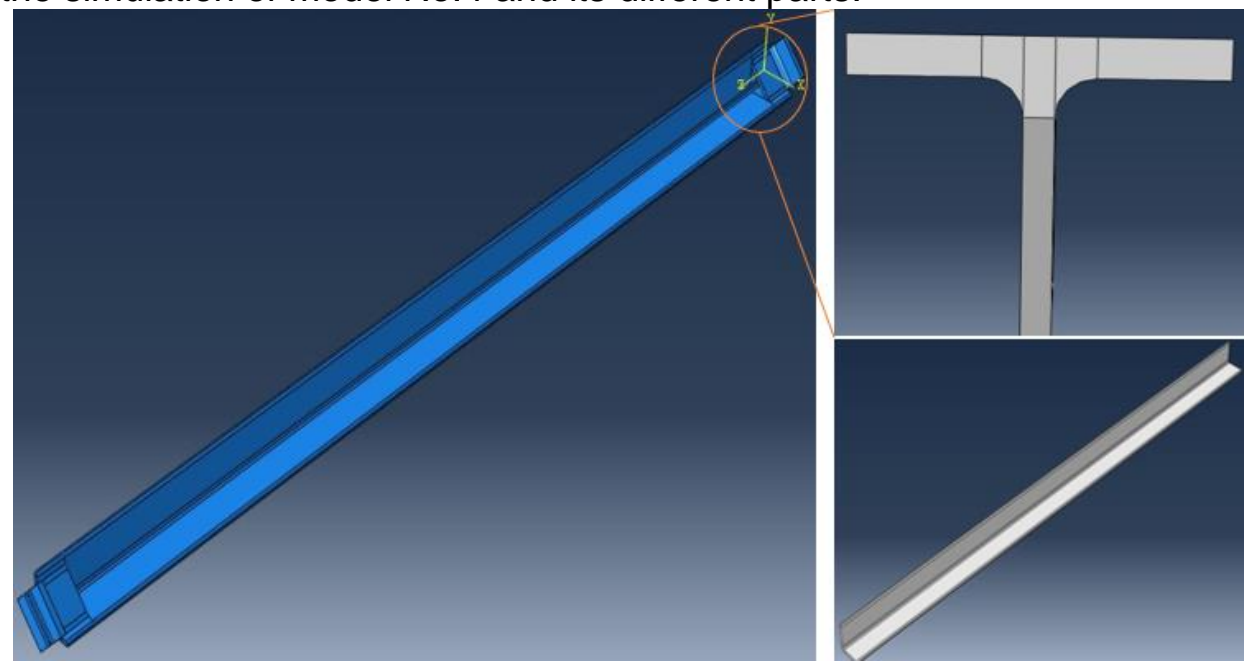

Fig. 6-the simulation of model No.4 (assembled and different parts)

\section{Type of analysis}

In this study the method used for analysis was the general nonlinear static analysis method which ignores the inertial effects and time-dependent behaviors of the material. These two assumptions are also set forth in construction design codes. The main reason for selecting this method for the analysis is to establish a condition that is as close as possible to the construction code requirements. In the analysis method, the materials were assumed to be solid and homogeneous with 3D stresses and strains.

The variables used for modelling were:

Independent variables: forces applying on the structure and the techniques used for connecting the angles and the T-bars (tees)

Dependent variables: the maximum force which none of the elements failed in it.

Research constants: angle and T-bar sizes, section materials, a method of analysis, loading type and duration, boundary conditions, and type of the supports used.

\section{Connections}

A constraint called "tie" was used for joining the T-bars to the angle. This constraint, which is used frequently in the modelling of civil engineering problems, can combine two surfaces with different meshing by making all the six degrees of freedom (DOFs) in one surface dependent to the other surface [22].

\section{Applied loads and supports}

To apply loads on the simulation models, loading components of the laboratory jack was used. In general, laboratory jacks have one movable jaw and one fixed jaw. The load is applied from the movable jaw of the jack to the test specimen and, at the same time, the fixed jaw of the jack develops a reaction to this load along the line of action of the applied force. Also, upon applying compression to the specimen by the jack, a friction connection is developed between the 
jack jaw and the parts of the specimen that are in contact with the jaw. This friction would prevent the contact surface on the specimen from moving along any direction but the loading direction.

In this apparatus, the load is applied to the surface of one of the T-bars. Therefore, the outer surface of a T-bar was selected and the compression load was applied to the same surface (as in the case of the movable jaw). Figure 7 shows the place of the applied load.

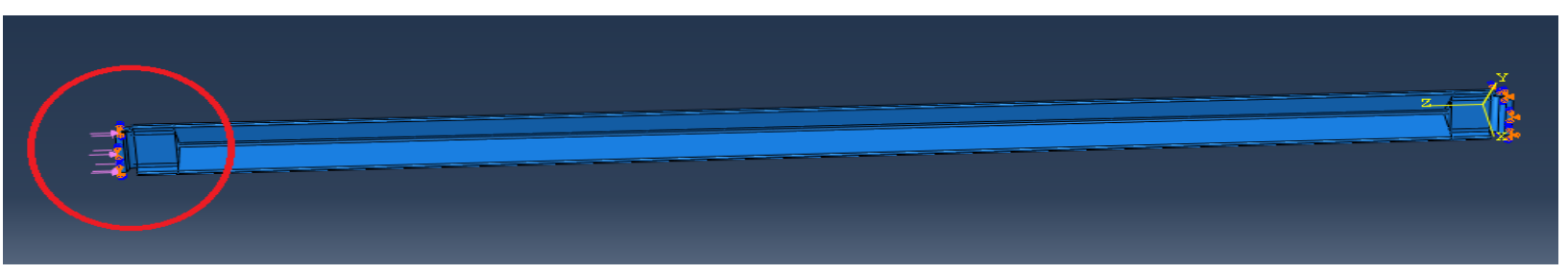

Fig. 7- Point of action of the applied load

On the opposite side, deflection along the z-axis -which is the line that the force is applied to- on the outer surface of the T-bar is prevented. Figure 8 shows the support oriented along the zaxis.

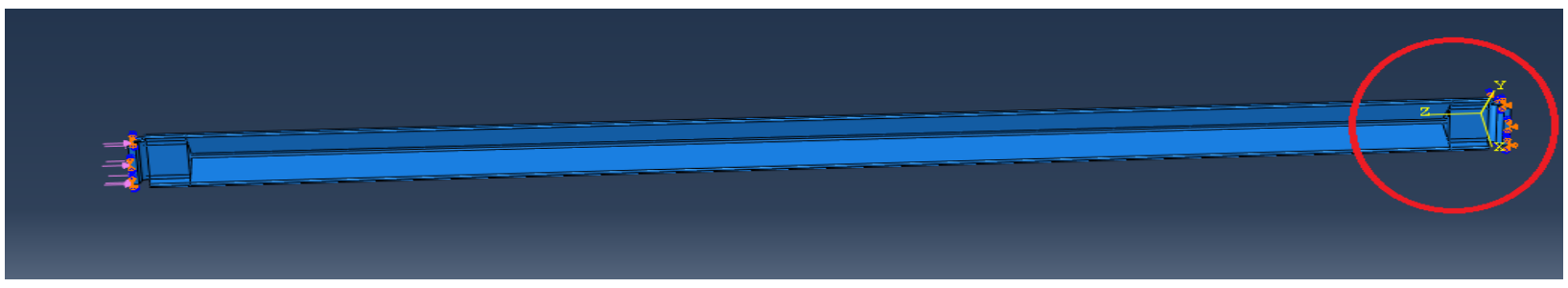

Fig. 8 - Support oriented along the line of action of the applied load

To examine the effect of the friction joint referred to above on the outer surface of the flanges at the end of T-bars, displacement was prevented along the $x$ and $y$-axes. As shown in Figure 9, this support is defined at both ends of the models.
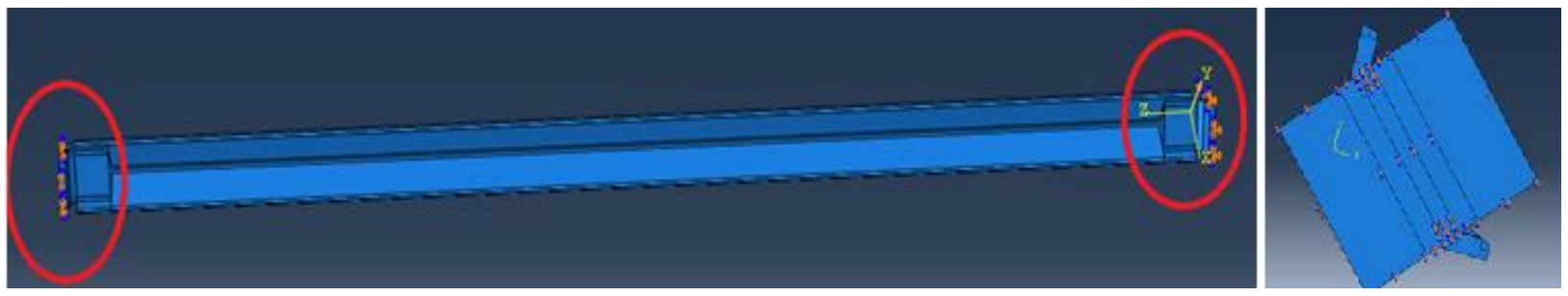

Fig. 9 - Supports oriented concerning $x$ and $y$ directions

In other words, both ends were fully restrained (translations and rotations) except the axial translation of the load-applying end [23]. This method of applying load and defining boundary conditions is conventional in many numerical investigations. For example, Poursharifi et al. (2020) [24]and El-Kholy et al. (2019) [23] used this method in their numerical studies.

Since the applied force was the most important independent variable in each model, to achieve the objective of the present study, the value of the distributed compressive load applied to the flange surface of one T-bar was changed, followed by observing and analyzing the corresponding models and their outputs. Loading was started at $20 \mathrm{~N} / \mathrm{mm}^{2}$ and was decreased by $0.25 \mathrm{~N} / \mathrm{mm}^{2}$ in each analysis. Besides, the maximum amount of load in which the stress of all of the elements of the model remained below the yield strength by applying it, was measured and 
recorded. It has to be noted that this is a comparative study and the results are approximated. Table 3 illustrates the brief information related to numerical modelling.

Tab. 3 - Brief of input in numerical software

\begin{tabular}{|c|c|c|c|}
\hline Modeling Space: & 3D, deformable & Young's Modulus: & $201035.5 \mathrm{Mpa}$ \\
\hline Base Feature: & Solid, Homogeneous & Poisson's Ratio: & 0.3 \\
\hline Method of Analysis: & Nonlinear & Mass Density: & $7850 \mathrm{Kg} / \mathrm{m} 3$ \\
\hline Type of Analysis: & Static, General & Yield Point: & $230.8 \mathrm{MPa}$ \\
\hline $\begin{array}{l}\text { Type of } \quad \text { Element } \\
\text { Analysis: }\end{array}$ & Standard,3D Stress & Number of steps: & 2 (initial and step1) \\
\hline Job Type: & Full Analysis & Independency: & Dependent \\
\hline Load Distribution: & Uniform & $\begin{array}{l}\text { Type } \quad \text { Bounc } \\
\text { Condition: }\end{array}$ & $\begin{array}{l}\text { Displacement/Rotatio } \\
\mathrm{n}\end{array}$ \\
\hline Load Type: & Pressure & Large Displacements: & Considered \\
\hline Material Behavior: & Isotropic & Type of Connection: & Tie \\
\hline
\end{tabular}

\section{Validation of results}

Experimental results of sample No.5 (the most optimized model) are used to verify the efficiency of the FEM model. To verify, the experimental type of the force-displacement curve of sample No.5 is compared to the computer-based type of it. Figure 10 includes both curves. However, in the numerical investigation the maximum force applied to the models is just over 9.81 $\mathrm{KN}$, the greatest force applied on sample No.5 for verification is $19.61 \mathrm{KN}$ (to ensure the accuracy of modelling). This method of validation is conventional in steel study. For example, FENG Ningning et al (2018) [25]compared finite element analysis results with experimental data in their study to verify their FEM modelling.

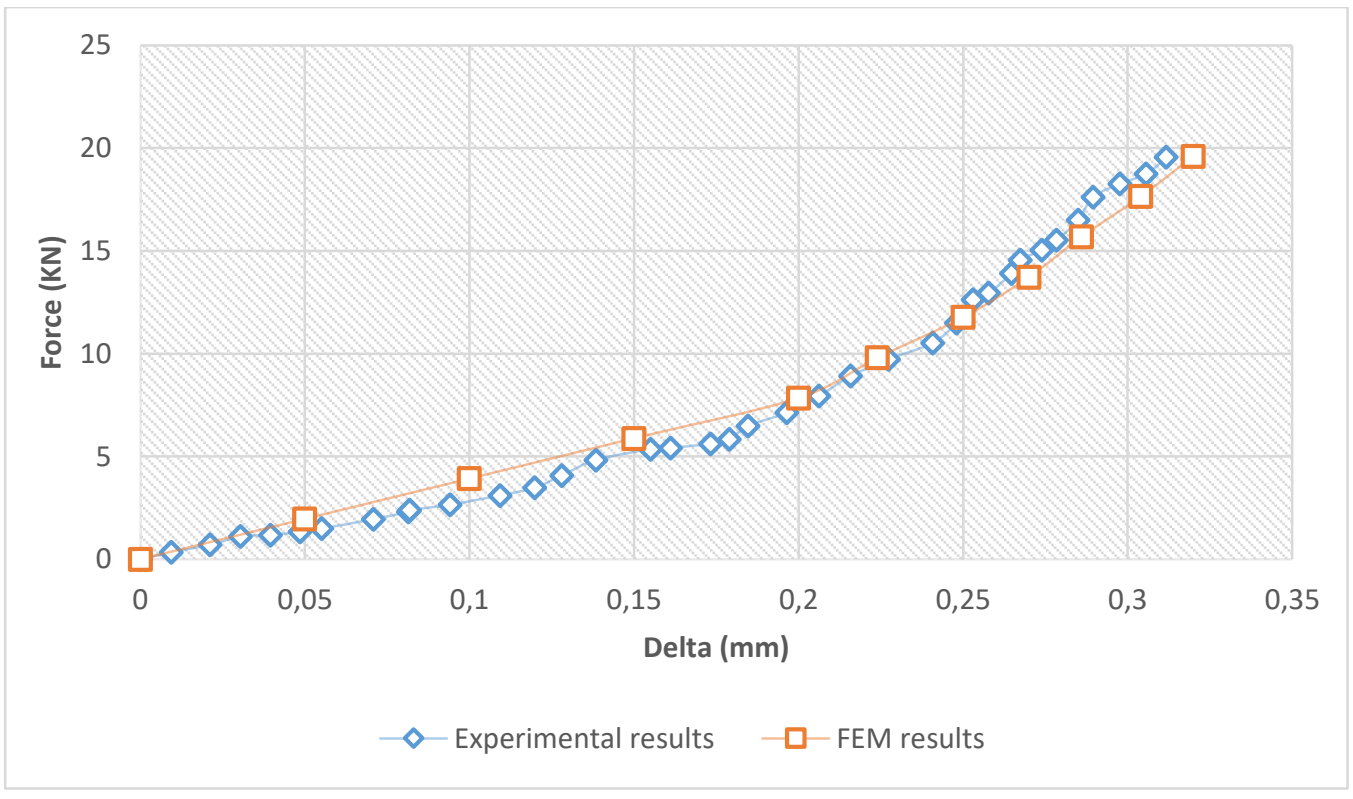

Fig. 10- Comparison of results 


\section{Results of computer modelling}

The results of the computer simulation are given in Figure 11. The force mentioned in the figure is the force under which none of the elements reached yield strength. The figure also presents the distribution of the applied forces on the T-bar flange surface. Model No.3 requires the lowest force for its first element shows plastic behavior but sample No.5 requires the highest force. Analysis of the models in ABAQUS was continued until the element started behaving plastically.

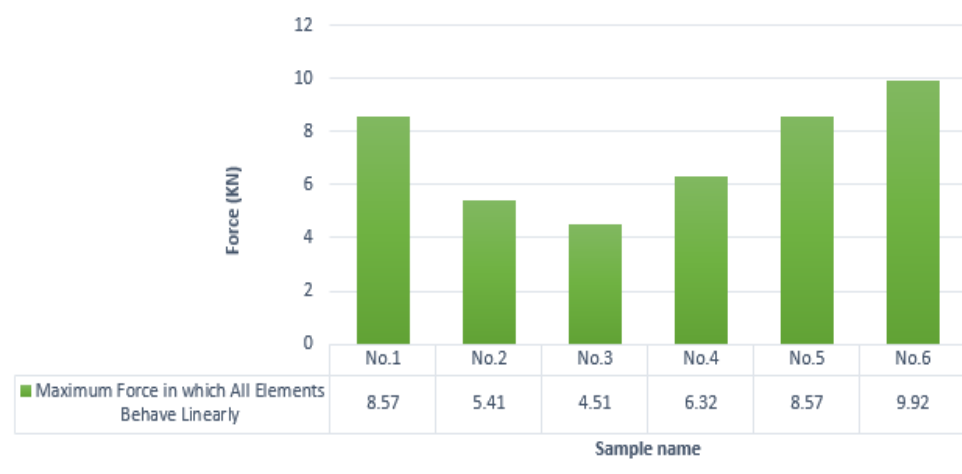

Fig. 11 - Modelling results

Also, Table 4 illustrates the stress concentration spots in all of the samples. This may help engineers who want to use one of the mentioned models to recognize the critical regions. As can be seen in Table 4, in all samples, stress concentrations occurred from about the T-bar profiles.

Tab. 4 - The places of stress concentrations

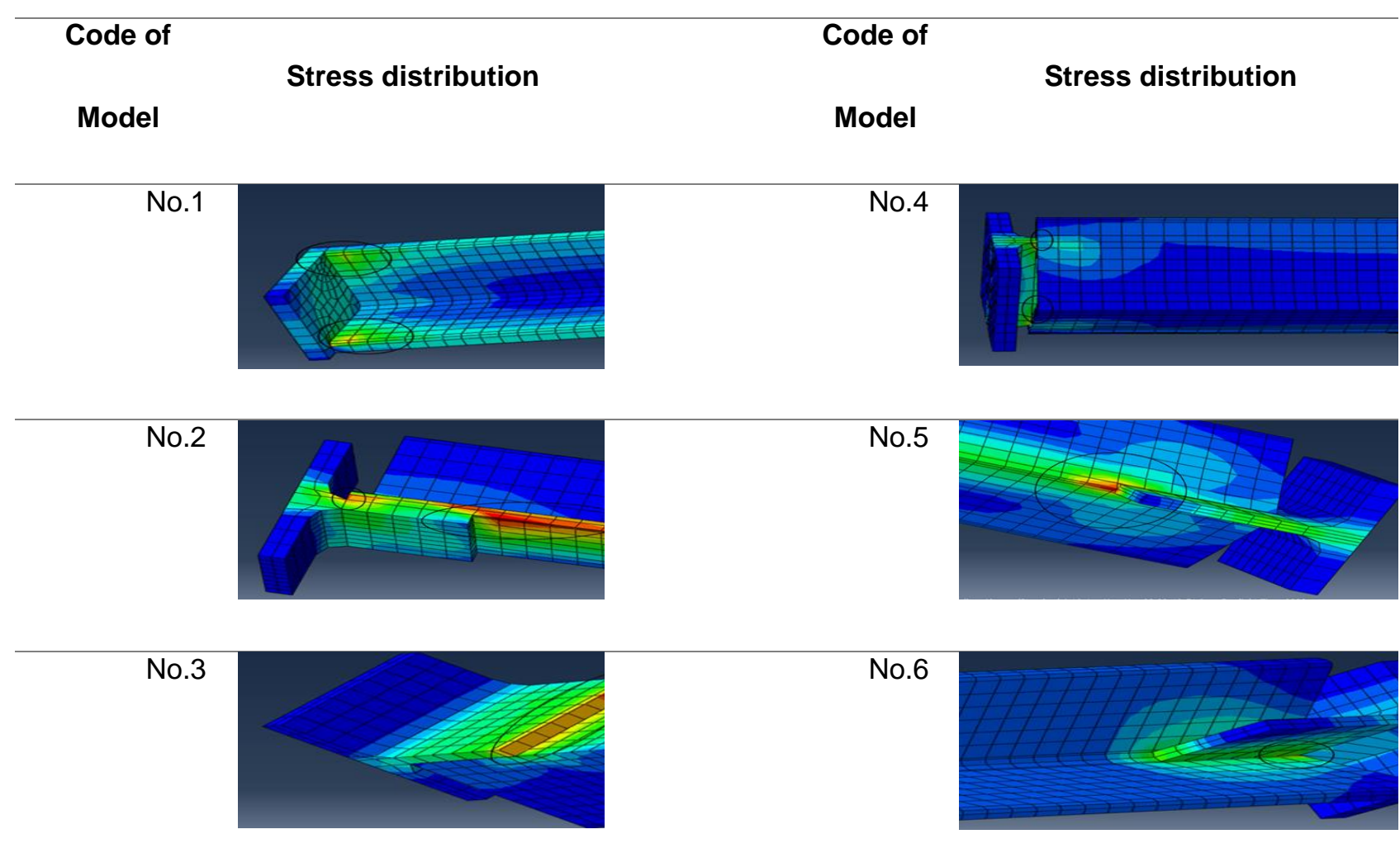


Each sample experiences three stages during the loading process from applying load to buckling. In the first stage, all elements of the sample behave linearly until an element starts to behave plastically. In the second stage, the stiffness of the element decreases and as a general rule, the force distributes among the elements based on their stiffness (the more stiffness, the more stress). This causes more elements to show plastic behavior. The last stage is buckling. By comparing the experimental results with the numerical results, it is realized how much of the plastic potential of a sample was used before buckling. In other words, if "the maximum force in which all elements behave linearly" of a sample is much lower than the "Bearing capacity", the sample is more efficient economically because it uses more plastic potential. The summary of experimental and computer-based modelling is shown in Table 5.

Tab. 5 - The summary of results

\begin{tabular}{ccccc}
\hline $\begin{array}{c}\text { sample } \\
\text { name }\end{array}$ & $\begin{array}{c}\text { Bearing capacity } \\
\text { (experimental) } \\
\text { (column 2) }\end{array}$ & $\begin{array}{c}\text { maximum force in which } \\
\text { all elements behave } \\
\text { linearly (FEM) }(\text { column 3) }\end{array}$ & $\begin{array}{c}\text { Differences between } \\
\text { column 2 and 3 }\end{array}$ & $\begin{array}{c}\text { the ratio of column } \\
\text { 3 to column 2 }\end{array}$ \\
\hline No.1 & $54.82(\mathrm{KN})$ & $8.57(\mathrm{KN})$ & $46.25(\mathrm{KN})$ & $15.64 \%$ \\
\hline No.2 & $38.15(\mathrm{KN})$ & $5.41(\mathrm{KN})$ & $32.73(\mathrm{KN})$ & $14.19 \%$ \\
\hline No.3 & $35.21(\mathrm{KN})$ & $4.51(\mathrm{KN})$ & $30.69(\mathrm{KN})$ & $12.81 \%$ \\
\hline No.4 & $26.38(\mathrm{KN})$ & $6.32(\mathrm{KN})$ & $20.06(\mathrm{KN})$ & $23.94 \%$ \\
\hline No.5 & $51.39(\mathrm{KN})$ & $8.57(\mathrm{KN})$ & $42.82(\mathrm{KN})$ & $16.68 \%$ \\
\hline No.6 & $31.68(\mathrm{KN})$ & $9.92(\mathrm{KN})$ & $21.75(\mathrm{KN})$ & $31.33 \%$ \\
\hline
\end{tabular}

\section{CONCLUSION}

Plenty of studies have been conducted about single angle. This fact can demonstrate the importance of angle profile in construction industry and researchers' appetite to know about the behavior of the profile. This study focuses on an omitted area: The position of gusset plate. The aim of this paper was to find a practical and innovative manner to increase the baring capacity of single angle compressing member without increasing the weight of the member by concentrating on joining area. However, further studies in different single angle boundary condition are necessary. Gaining profound insight into seismic and static behavior of this profile not only can be beneficial economically, but also can provide an opportunity for engineers to design highperformance structures.

It is conventional to connect gusset plates to the flanges of the single angle (like sample No.2 and sample No.3), especially in steel structure braces. However, according to this study, it is recommended to install gusset plates on single angle like model No.5. In other words, if the angle between the gusset plates and each of the flanges of the single angle is $45^{\circ}$ and the gravity center of the gusset plate is alleged with that of the single angle, the optimal joint will be provided. Figure 12 illustrates the optimum connection. The specific results are mentioned as follows. 
Fig. 12- The schematic illustrator picture of optimal installation according to this study

In the present study, laboratory tests were conducted to determine the highest load-bearing capacity of a single angle column with using various loading conditions on one or two legs. It is concluded that the highest compressive strength is related to model 1 , while the lowest compressive strength is related to model No.4. Besides, by comparing the experimental and FEM results, it can be stated that the angel which its first element enters the plastic area with less power, will not necessarily fail with less power. Regarding the point that gusset plates are placed orthogonal to the section, the most useful and optimized model will be model No .5.

The load-bearing capacity of sample No .1 is the highest, and all samples were failed because of buckling. Consequently, it can be said that gusset plate installation, which is inevitable in particular for braces and members of a truss, can contribute to a reduction of critical buckling force.

Samples No .4 and No .6 had the worst performances not only because they had the lowest load-bearing capacity but also because the ratio of maximum force in which all elements behave linearly to load-bearing capacity was high (23.94\% and $31.33 \%$, respectively). It implies that the larger proportion of the plastic capacity of the samples were not used before buckling.

Table 3 demonstrates the critical regions of all samples under loading which can be beneficial for anyone who wants to use the mentioned methods of installation of a gusset plate to a single angle. In Sample No.5 stress concentration occurred at the end of the gusset plate (web of T-bar).

\section{REFERENCES}

[1] Jain, A., Rai, D.C., 2014. Lateral-torsional buckling of laterally unsupported single angle sections. Journal of Constructional Steel Research, vol. 102: 178-189. DOI:

http://dx.doi.org/10.1016/j.jcsr.2014.06.013.

[2] Botelho. I. et al., 2021. Starred rolled stainless steel angle sections under compression: An experimental and numerical investigation. Thin-Walled Structures, vol. 158, pp. 1-17 DOI: https://10.1016/j.jcsr.2012.10.009

[3] Simonian, V., Majrouhi Sardroud, J., 1997. Investigation into the stability of single angle. Journal of Faculty of Engineering, vol. 18: 29-46.

[4] Hussain, A., Liu, Y.P., Chan, S.L., 2018. Finite Element Modeling and Design of Single Angle Member Under Bi-axial Bending Structures, vol. 16: 373-389. DOI:

https://doi.org/10.1016/j.istruc.2018.11.001.

[5] Shukla. K. et al., 2021. Failure Analysis of a Cruciform-Leg Transmission Line Tower. International Journal of Steel Structures, vol. 17, pp. 1127-1141. DOI: https://doi.org/10.1007/s13296-021-00454-5

[6] Sayed, A.M., 2020. Numerical analysis of single-angle steel member under tension load with damage in the unconnected leg. Structures, vol. 25, 920-929. DOI: https://doi.org/10.1016/j.istruc.2020.04.001.

[7] Paiva, F., Barros, R.C., 2020. PARAMETRIC STUDY OF THE BUCKLING RESISTANCE OF A 
SINGLE ANGLE IN OPENSEES, vol. 16: 373-389. Porto.

[8] Guo, X., et al., 2020. Mechanical behavior of in-service axial compression angle steel members strengthened by welding. Journal of Building Engineering, vol. 32, pp. 1-16. DOI:

https://doi.org/10.1016/j.jobe.2020.101736

[9] Mirtaheri, M., et al., 2019. Numerical investigations on elastic buckling and hysteretic behavior of steel angles assembled buckling-restrained braces. Structural Engineering and Mechanics, vol. 70(4): 381 394. DOI: https://doi.org/10.12989/sem.2019.70.4.381

[10] Tong, J., Guo, Y., 2018. Mitigation of progressive collapse in steel structures using a new passive connection. Journal of Constructional Steel Research, vol. 144: 21-39. DOI:

https://doi.org/10.12989/sem.2019.70.4.381

[11] Tian, L., et al., 2018. Single-Angle Compression Members with Both Legs Bolted at the Ends: Design Implications from an Experimental Study. Journal of Structural Engineering, vol. 144(9): 381-394. DOI: https://doi.org/10.1061/(ASCE)ST.1943-541X.0002158

[12] Kettler, M., Taras , A.,Unterweger, H., 2017.Member capacity of bolted steel angles in compression - Influence of realistic end supports.Journal of Constructional Steel Research, vol. 130: 22-35.

DOI:http://dx.doi.org/10.1016/j.jcsr.2016.11.021.

[13] Brando, G.,De Mattei, G., 2013. Buckling resistance of perforated steel angle members. Journal of Constructional Steel Research, vol. 81: 52-61. DOI: https://doi.org/10.1016/j.jcsr.2012.10.009.

[14] Aydin, R.,et al., 2011. Experimental and code based study of beam-column behaviour of equal leg single-angles. Journal of Constructional Steel Research, vol. 67(5): 780-789. DOI: https://doi.org/ 10.1016/j.jcsr.2010.12.016.

[15] Liu, Y. Hui, L., 2010. Finite element study of steel single angle beam_columns. Engineering Structure, vol. 32(8): 2087-2095. DOI: https://doi.org/10.1016/j.engstruct.2010.03.009.

[16] Liu, Y., Hui, L.,2008. Experimental study of beam-column behaviour of steel single angle Journal of Constructional Steel Researc, vol. 64(5): 505-514.

[17] P.-S. Lee, H.-C. Noh., C.-K. Choi, "Geometry-dependent MITC method for a 2-node iso-beam element," Structural Engineering and Mechanics, vol. 29, no. 2, pp. 203-221, 30 May 2008. DOI: 10.12989/sem.2008.29.2.203.

[18] J. Reddy, An Introduction to the Finite Element Method. Inc. USA: McGraw-Hill Book Company, 1993.

[19] ASTM A370.,2010. Standard Methods and definitions for Mechanical Testing of Steel Products. American Society for Testing and Materials; West Conshohocken, Pennsylvania, United States.

[20] AISC ,2000. Load and Resistance Factor Design Specification for Single-Angle Members. American Institute of Steel Construction, Inc; Chicago, United States.

[21] Anbarasu, M., Bharath Kumar, S., Sukumar, S., 2013. Study on the effect of ties in the intermediate length Cold Formed Steel (CFS) columns. Structural Engineering and Mechanics, vol. 46(3): 323-335. DOI:http://dx.doi.org/10.12989/sem.2013.46.3.323

[22] Zaghian M. H., majrouhi sardrod j., 2015. Investigation into the Behavior of Comparison Single Angle Subject to Various Loading Condition Using Computer-Base Modelling. International Congress on Civil Engineering ,Architecture \&Urban development. Tehran, desember.

[23] El-Kholy, A.M., et al.,2019. Finite element simulation for steel tubular members strengthened with FRP under compression. Structural Engineering and Mechanics, vol. 72(5): 569-583. DOI: https://doi.org/10.12989/sem.2019.72.5.569.

[24] Poursharifi, M., et al., 2020. Introducing a new all steel accordion force limiting device for space structures", Structural Engineering and Mechanics, vol. 74(1): 69-82. DOI:

https://doi.org/10.12989/sem.2020.74.1.069.

[25] F. Ningning, et al., 2018. THE EFFECT OF AXIAL COMPRESSION RATIO ON SEISMIC BEHAVIOR OF INFILLED REINFORCED CONCRETE FRAMES WITH PROFILED STEEL SHEET BRACING. THE CIVIL ENGINEERING JOURNAL, vol. 2018: 439-449. DOI: https://doi.org/10.14311/CEJ.2018.03.0035 